UDC 338.4

LBC 65.291 .2

\title{
EVALUATION OF THE QUALITY \\ OF PRODUCTION ENTERPRISE MANAGEMENT IN THE DIGITAL ECONOMY
}

\author{
Roman M. Kachalov \\ Central Economics and Mathematics Institute, RAS, Moscow, Russian Federation \\ Yuliya A. Sleptsova \\ Central Economics and Mathematics Institute, RAS, Moscow, Russian Federation
}

\begin{abstract}
The quality of enterprise management is mainly determined by the enterprise's ability to adapt to changing environmental conditions. Over the recent years, significant progress has been made in processing large amounts of information. This is due to the exponential increase in processing power and the availability of huge amounts of data. The introduction of digital technologies provides new opportunities for rapid response to inquiries and consumer behavior. The scale of changes and the timing of the implementation of projects on the introduction of digital technologies can be an indicator for assessing the quality of enterprise management. To assess the quality of management, it is necessary to have a clear idea of an enterprise's location, its development prospects and the projects which can contribute to achieving the goal. The quality of enterprise management includes, in addition to the quality of the management system, the quality of products, services and processes, including technological and business processes. The methods of management and organizational structure of enterprises in the digital economy may differ from traditional models. This paper deals with enterprises at which the activity of employees is built on the principles of decentralization and self-organization. Risk factors for the introduction of new technologies in an enterprise as a complex socio-economic system, are grouped by sources of risk in subsystems. Taking into account the variety of initial conditions, the state of the subsystems of the enterprise and the goals set, the identification of risk factors depends essentially on the quality of the management system, the specifics of the activities and organization of information systems. The high quality of management system for successful enterprises allows assessing the overall level of risk before launching the next wave of change, the most promising initiatives and critical risk factors that can prevent it.

Key words: corporate economics, quality of management, economic risk factor, social and human capital, digital technologies.

Citation. Kachalov R.M., Sleptsova Yu.A. Evaluation of the Quality of Production Enterprise Management in the Digital Economy. Vestnik Volgogradskogo gosudarstvennogo universiteta. Seriya 3, Ekonomika. Ekologiya [Science Journal of Volgograd State University. Global Economic System], 2018, vol. 20, no. 3, pp. 50-60. (in Russian). DOI: https://doi.org/10.15688/jvolsu3.2018.3.6
\end{abstract}

\section{ОЦЕНКА КАЧЕСТВА УПРАВЛЕНИЯ} ПРОИЗВОДСТВЕННЫМ ПРЕДПРИЯТИЕМ В ЦИФРОВОЙ ЭКОНОМИКЕ

\author{
Роман Михайлович Качалов \\ Центральный экономико-математический институт РАН, г. Москва, Российская Федерация \\ Юлия Анатольевна Слепцова \\ Центральный экономико-математический институт РАН, г. Москва, Российская Федерация
}


Аннотация. Качество управления предприятием во многом определяется возможностями предприятия адаптироваться к изменяющимся условиям внешней среды. За последние годы был достигнут существенный прогресс в обработке больших массивов информации, обусловленный экспоненциальным увеличением вычислительной мощности и наличием огромных объемов данных. Внедрение цифровых технологий предоставляет новые возможности для быстрого реагирования на запросы и поведение потребителей. Масштаб изменений и сроки реализации проектов по внедрению новых цифровых технологий могут стать индикатором для оценки качества управления предприятием. Для этого необходимо четкое представление о том, в какой точке находится предприятие сейчас, в каком направлении двигается и какие проекты могут позволить достичь цели. Качество управления предприятием определяется не только качеством собственно системы управления, но и качеством продукции, услуг и процессов, включая технологические и бизнеспроцессы. Методы управления и организационная структура предприятий в цифровой экономике могут отличаться от традиционных методов управления и организационных структур. В работе рассмотрены предприятия, деятельность сотрудников которых построена на принципах децентрализации и самоорганизации. Факторы риска внедрения новых технологий в сложной социально-экономической системе, которую представляет собой предприятие, сгруппированы по источникам риска в подсистемах. Учитывая многообразие начальных условий, состояния подсистем предприятия и поставленных целей, выявление факторов риска существенно зависит от качества системы управления, специфики деятельности и организации информационных систем. Высокое качество системы управления успешными предприятиями позволяет оценить общий уровень риска перед запуском следующей волны изменений, определять перспективные инициативы и выявлять критические факторы риска, которые могут помешать реализации этих инициатив.

Ключевые слова: экономика предприятия, качество управления, фактор экономического риска, социальный и человеческий капитал, цифровые технологии.

Цитирование. Качалов Р. М., Слепцова Ю. А. Оценка качества управления производственным предприятием в цифровой экономике // Вестник Волгоградского государственного университета. Серия 3, Экономика. Экология. -2018. - Т. 20, № 3. - С. 50-60. - DOI: https://doi.org/10.15688/jvolsu3.2018.3.6

\section{Введение}

Происходящие в обществе технологические перемены по своей сложности не имеют исторических аналогов. Можно выделить три признака, характеризующих нынешний период: скорость изменений, их масштаб и влияние на все социально-экономические системы. В то же время экономика становится все более глобальной и взаимосвязанной, а вследствие этого - менее предсказуемой. Скорость изменений затрагивает практически каждую отрасль, а масштаб этих изменений может вызвать глубокие преобразования промышленных предприятий и их систем управления. За последние годы был достигнут существенный прогресс в обработке больших массивов информации, обусловленный экспоненциальным увеличением вычислительной мощности и наличием огромных объемов данных. Внедрение цифровых технологий предоставляет новые возможности для быстрого реагирования на запросы и поведение потребителей. В ближайшем будущем ожидается, что технологические инновации могут приве- сти к дальнейшему увеличению эффективности производства и повышению производительности труда при снижении логистических и коммуникационных расходов.

В то же время у руководителей предприятий появляются новые вопросы: каким образом не только не потерять управляемость, но и повысить качество управления предприятием; какие новые факторы риска, влияющие на качество управления, возникают при внедрении цифровых технологий и т. п. Поэтому проблема повышения качества управления предприятием в цифровой экономике представляется все более актуальной.

Цель данной работы состоит в исследовании проблем совершенствования качества управления экономическими объектами при внедрении цифровых технологий. При этом инструментальная часть исследования базируется на системной экономической теории Г.Б. Клейнера [6] и операциональной теории управления риском $[1 ; 3]$.

Понятие качества управления предприятием подразумевает наличие нескольких уровней [11]: качество системы управления 
предприятием, как единой социально-экономической системы; качество управления структурными подразделениями; качество функционального управления производством, маркетингом, реализацией готовой продукции, снабжением и т. п.; качество управления человеческим капиталом предприятия; качество управления материальными, информационными и энергетическими ресурсами. Также в этом контексте необходимо рассматривать управление качеством продукции и бизнес-процессов на предприятии. Наряду с этим в рамках внедрения цифровых технологий понятие «качество управления» следует рассматривать как интегрированную характеристику умения сотрудников предприятия успешно вести бизнес [10]. Не менее важно анализировать качество управления как целостный процесс разработки, принятия и реализации решений, которые в совокупности обеспечивают конкурентоспособность предприятия и позволяют ему успешно адаптироваться к изменяющимся условиям внешней среды [8].

Появившийся сравнительно недавно термин «цифровая экономика» можно трактовать двояко. С одной стороны, это область экономики, которая связана с производством и реализацией электронных товаров и услуг, например, с реализацией прав доступа к печатным изданиям в цифровом формате, музыкальным файлам, осуществлением электронной подписки на газеты и телеканалы, получением онлайн услуг образования или телемедицины. С другой - возможен и более широкий подход к понятию «цифровая экономика», который подразумевает влияние на экономическую деятельность результата трансформационных эффектов технологий общего назначения в области информации и коммуникаций [21].
Качество управления предприятием характеризуется не только качеством системы управления, но также эффективностью управления качеством продукции, услуг и процессов, включая технологические и бизнес-процессы (см. рисунок). Так, например, внедрение PLM-систем (Product Lifecycle Management), управляющих жизненным циклом изделия или продукта, и ВРМ систем (Business Process Management), сопровождающих управление деловыми процессами, повышает качество управления предприятием в режиме реального времени в той части, которая касается управления качеством продукции и качеством бизнес-процессов.

В узком смысле под качеством управления предприятием можно понимать степень соответствия этой деятельности общепризнанным требованиям или стандартам. Например, сертификаты, которые может получить предприятие, удостоверяют, что принятая на предприятии система управления качеством продукции или система экологического менеджмента соответствует российским и международным стандартам. Для получения таких сертификатов проводится специализированный аудит, который позволяет подтвердить квалифицированный и комплексный подход при создании и управлении бизнес-процессами в соответствии с передовой международной практикой, реализованной в требованиях стандартов систем менеджмента. Как правило, такая сертификация соответствия продукции требованиям стандартов, а также самих процессов ее изготовления, осуществляется предприятиями на добровольной основе.

В то же время формирование прикладных методов оценки качества системы управления предприятием успешно реализуется

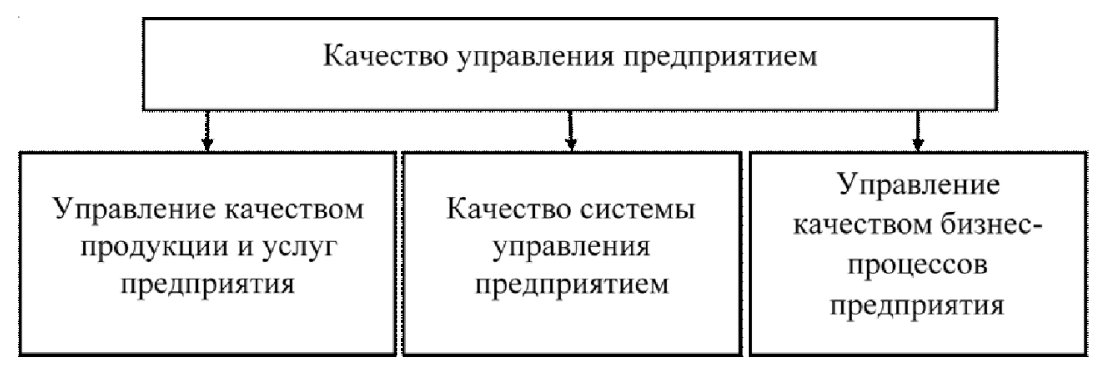

Рисунок. Компоненты качества управления предприятием

Примечание. Составлено авторами. 
средствами риск-менеджмента и, в частности, применением операциональной теории управления экономическим риском [3]. В рамках этой теории разработаны и активно применяются методы идентификации факторов экономического риска, а также широкий арсенал методов разработки адекватных антирисковых управляющих воздействий и программ антирисковых мероприятий [17].

При оценке качества управления предприятием в процессе внедрения цифровых технологий анализируется способность руководства предприятия к целеполаганию и, в частности, к изменению целей и задач, вызывающих наступление перемен [16]. Именно эти перемены приводят к появлению функций и методов управления изменениями, к инициированию исследований реакции предприятия на перемены во внешней среде. То есть структура предприятия и руководящие кадры начинают адаптироваться к изменениям на всех уровнях управления. При анализе ситуаций и рассмотрении возникающих проблем современные системы управления предприятием позволяют предвидеть серьезные изменения во внешней среде и принимать заблаговременно соответствующие решения, предписывающие отказ от устаревших видов продукции или услуг. Качество системы управления при этом также может характеризоваться наличием необходимого информационного обеспечения процедур планирования и контроля изменений на предприятии, а также параметрами принятой на предприятии коммуникационной политики.

Если основным стимулом системы управления является применение штрафов и в качестве базового стимула применяется наказание за ошибку, то естественной реакцией сотрудников, как элементов управляемой подсистемы, будет самозащита. Развитие новых технологий неизбежно порождает сбои в ходе их реализации на уровне рядовых работников. А сотрудники, которым приходится защищаться после допущенной (незлонамеренной!) ошибки, иногда предпочитают искажать информацию, передаваемую по каналам обратной связи к руководству. В таком случае последующие управленческие решения будут приниматься на основе некорректной информации, что, естественно, снижает уровень ка- чества системы управления предприятием. В качестве противоположного применению санкций примера может быть рассмотрена система управления, в основу которой заложена социальная безопасность, строящаяся на принципах доверия. В этом случае сбои не исключаются, меняется реакция на ошибку как самого сотрудника, так и системы управления. Руководство предприятия получает полную и неискаженную информацию во всех случаях возникновения неблагоприятных событий, как крупномасштабных, так и более мелких, располагает достоверной информацией, а предприятие в целом получает возможность наилучшим способом адаптироваться к внешним и внутренним изменениям. Следовательно, можно сказать, что стиль и культура управления могут повлиять на достоверность информации, получаемой по каналам обратной связи и отразиться на качестве системы управления.

Таким образом, уровень социального и человеческого капитала предприятия, определяемый знаниями, компетенциями и свойствами, воплощенными в сотрудниках предприятия и эффективных коммуникациях между ними, способствующими созиданию социального и экономического благополучия предприятия, оказывают влияние на качество управления [19].

\section{Новый подход к социальному и человеческому капиталу}

\section{в условиях цифровизации экономики}

Проблема оценки качества управления предприятием наиболее выпукло может быть представлена на примере предприятий, поле деятельности которых непосредственно связано с «цифровыми технологиями», то есть с производством программного обеспечения, контента для интернет-платформ и смежных высокотехнологичных областей. В соответствии с нормативными актами сильными сторонами такого рода предприятий, выпускающих высокотехнологичную продукцию и услуги, то есть продукцию и услуги, при производстве которых используются новейшие технологии (п. 1 Приказа Министерства образования и науки РФ от 1 ноября 2012 г. № 881 [14]), являются как инновационный характер произ- 
водимой продукции и/или предоставляемых услуг, так и высокая профессиональная подготовка сотрудников.

Методы управления инновационным предприятием могут отличаться от общепринятых методов управления. Например, для предприятия, предоставляющего высокотехнологические услуги связи, в первую очередь важной функцией управления деятельностью становится непосредственное взаимодействие с производителями технологического оборудования, то есть активное участие в создании инновационных технических средств реализации услуг связи, а уже во вторую - собственно деятельность по предоставлению услуг связи и видеоконтента [7]. По мнению некоторых экспертов, использование методов обработки больших объемов данных (так называемых Big Data), инструментов блокчейна и машинного обучения способно радикально повысить производительность труда, поэтому так важно в рамках системы управления предприятием формировать социальный и человеческий капитал предприятия [22; 24].

Традиционно на промышленных предприятиях организационная структура выстраивается иерархически, по принципу «сверху-вниз», от высшего руководства к среднему звену и далее до рядовых сотрудников. Примером самой консервативной организационной структуры этого типа можно считать модель, в которой правила деятельности предприятия определяются одним человеком - собственником или руководителем предприятия. Большинство крупных современных предприятий, наделенных иерархической организационной структурой, построены на основе конкуренции персонала, а также на системе поощрений и наказаний сотрудников. При этом, несмотря на жесткую организационную структуру, могут поощряться новые идеи сотрудников и их стремление к движению по карьерной лестнице. На следующей ступени развития организационных структур появились предприятия, для которых отношения сотрудничества внутри подразделений считались ценнее достигнутого результата, а польза для общества в целом была важнее прибыли для предприятия. Предполагалось, что этот тип организационной структуры придет на смену традиционным моделям, но такие предприятия оказа- лись не способны выдержать конкуренцию в условиях рынка.

Для построения так называемой «синергетической» или «бирюзовой» организации [10] каждый сотрудник должен стремиться к саморазвитию в рамках предприятия, а для этого необходимо четко сформулировать миссию предприятия и разъяснить ее сотрудникам. В основу таких предприятий заложены принципы децентрализации и самоорганизации, согласно которым каждый сотрудник имеет право принимать важные решения. На инновационных предприятиях эта модель организационного взаимодействия опирается на целостность объединения сотрудников, их способность к самоорганизации и эволюционному развитию. При этом обычно предпочитается достаточно гибкий подход к выстраиванию системы управления, поскольку такая модель работает существенно эффективней существующих иерархических систем, хотя и имеет ряд ограничений. Однако преимущество такой организационной структуры проявляется только в случае, если виды деятельности и процессы принятия решений дополняют друг друга таким образом, что совокупный эффект превышает простую сумму составных частей [9]. Следует заметить, что новый тип организационной структуры может позволить предприятию максимально быстро адаптироваться к изменениям внешней среды.

Однако деятельность, основанная на принципах децентрализации, подходит далеко не всем предприятиям, а принцип самоорганизации плохо внедряется в иерархических структурах, поскольку эти принципы должны быть приняты еще с момента зарождения предприятия. Этот тип организационной структуры хорошо зарекомендовал себя в таких сферах, как создание новых видов услуг или разработка программных продуктов. При этом за получение результата отвечают все сотрудники предприятия, без четко указанных должностей и утвержденных инструкций. Возникающий при этом синергетический эффект можно считать итогом совместного действия. При таком типе организационной структуры руководитель предприятия является репрезентативным лицом, непринимающим индивидуальных управленческих решений. 
К возможным факторам экономического риска (ФЭР), характерным для такой организационной структуры, можно отнести возможность проявления так называемой суммирующей отрицательной синергии, которая порождает негативные последствия. Например, сотрудник, обладающий высоким профессионализмом, может быть отторгнут коллективом, и результативность его деятельности окажется существенно ниже, чем предполагалось при его приеме на работу. Таким образом, синергию можно также трактовать как своего рода координацию или взаимосвязанное сотрудничество, которые проявляются в форме стратегического партнерства или кооперации.

Отрицательный синергетический эффект возникает также как результат взаимодействия составных элементов предприятия, например, при эксплуатации устаревшего оборудования и новейших технологий, когда суммарный результат от их применения гораздо меньше, чем в случае использования несовременного оборудования и соответствующих технологий. Недостаток уровня квалификации сотрудников предприятия при работе на современном оборудовании и использовании передовых технологий также может дать отрицательный эффект, поэтому гармонизация элементов и факторов производства будет одной из важнейших задач при совершенствовании качества управления предприятием на всех уровнях.

\section{Оценка качества управления предприятием при внедрении цифровых технологий}

На этапе планирования проекта по внедрению цифровой технологии необходимо не только оценить влияние этой технологии на качество управления предприятием, но и спрогнозировать весь спектр возможных при этом факторов экономического риска. При разработке стратегий, предусматривающих применение цифровых технологий, руководство предприятия, с одной стороны, стремится к реализации новых возможностей, а с другой - должно осознавать, какие неблагоприятные события для предприятия могут помешать реализации цифровых технологий. Обе эти стороны внедрения цифровой технологии (новые возможности или неблагоприятные последствия) критически важны для оценки качества управления предприятием, так как в процессе разработки стратегии надо определить набор необходимых инициатив, дающих значительный экономический эффект в ближайшей перспективе и вместе с тем способствующих достижению долгосрочных целей предприятия.

Скорость изменений в обществе, обусловленных применением новых технологий, не может не влиять на видение собственников предприятия относительно путей его развития. Например, альтернативные источники энергии [13], компьютерное зрение [12] или блокчейн [15] широко обсуждались задолго до того, как эти технологии стали применяться в социальной и экономической сфере. Однако сложно выяснить, использование каких именно технологий может оказать кардинальное влияние на отрасль в будущем, и каким образом можно применить эти знания для формирования стратегии предприятия. С этой задачей тесно связана проблема адаптации предприятия к новым технологиям, поэтому предприятие вынуждено искать способы улучшения качества управления с учетом всех сложностей внутренней и внешней среды предприятия и действием возможных факторов экономического риска.

При внедрении цифровых технологий необходимы координация и обмен информацией между подразделениями предприятия, поэтому для выявления всего спектра возможных факторов экономического риска целесообразно воспользоваться системной экономической теорией [6]. Эта теория выделяет по пространственно-временному признаку четыре типа базовых социально-экономических систем: объектные, средовые, проектные и процессные [5]. Предприятие согласно этой теории относится к объектному типу социально-экономических систем. В то же время в пределах предприятия, как системного объекта, тот же пространственно-временной подход позволяет структурировать его, выделив те же четыре типа аналогичных подсистем [4].

Применение этого подхода к задаче совершенствования качества управления существенно облегчает выявление множества возможных факторов экономического риска, для нейтрализации которых в ходе внедрения циф- 
ровой технологии желательно предусмотреть превентивные меры. Кроме того, такой методический прием позволяет учитывать специфику каждой из выделенных подсистем предприятия, а также локализацию внедряемых цифровых технологий и присущих соответствующей подсистеме факторов экономического риска. Не претендуя на полноту охвата проблемы совершенствования качества управления предприятием в условиях цифровой экономики, можно на основании проведенных исследований сформулировать следующие методические положения, учитывающие характерные черты каждой из четырех выделенных подсистем предприятия:

1. Объем инноваций с точки зрения объектной подсистемы может быть ограничен. Например, в авиастроении - это высокая стоимость основного производственного оборудования и длинные жизненные циклы готовой продукции; кроме того, возможно негативное влияние на безопасность предлагаемых предприятием услуг. Внедрение новейших технологий в качестве антирисковых управленческих воздействий может повысить качество управления материальными ресурсами, но наличие устаревшего специализированного оборудования и программного обеспечения для информационных систем может стать причиной появления факторов риска, усиливающих значимость проблем обеспечения безопасности.

2. В результате внедрения цифровых технологий может произойти перераспределение центров прибыли или измениться способ ее генерации, что приведет к изменению характеристик всей процессной подсистемы предприятия. Например, разработчики крупногабаритной техники, подключенной к сети Интернет, и облачной инфраструктуры для ее поддержки постепенно могут захватить долю рынка сельскохозяйственных машин, которую в настоящее время занимают производители традиционного оборудования. Возможными центрами прибыли могут стать подразделения, предоставляющие те услуги, которые помогают руководителям принимать решения, такие как упоминавшийся выше анализ больших массивов данных (Big data), а также применение результатов этого анализа для разработки мероприятий по повышению произво- дительности труда. При внедрении новых информационных систем может потребоваться создание сложной многоуровневой инфраструктуры. Это обуславливается тем, что сбой в одном из компонентов информационного процесса может привести к цепочке отказов нескольких информационных систем и повлечь за собой серьезные негативные последствия для предприятия в целом.

Использование социальных сетей в качестве нового канала коммуникаций для взаимодействия со стейкхолдерами может помочь предприятию в максимальной степени учитывать интересы своих потребителей. Вместе с тем необходимо отметить, что для обеспечения безопасности цифровых технологических решений остается необходимым применение эффективных средств контроля [20]. В традиционных системах управления информационными и энергетическими потоками предприятий будет задействовано все больше и больше облачных интернет-приложений, что может повлечь за собой возникновение не встречавшихся ранее видов факторов экономического риска.

3. Â проектной подсистеме предприятию удастся достичь максимального эффекта, сосредоточив свои усилия по внедрению цифровых технологий, например, на взаимодействии с потребителями в электронном формате, которое будет ориентировано на определение и удовлетворение ожиданий потребителей [23]. Цифровые технологии, связанные с продукцией предприятия и сопутствующим сервисом, а также рутинной операционной деятельностью, в свою очередь могут генерировать специфические факторы риска недостижения целей функционирования принятой бизнес-модели предприятия. Параллельно во вспомогательных подразделениях предприятия могут проявиться такие факторы риска как: ФР неэффективной работы цифровых технологий; ФР недостаточного развития компетенций сотрудников, не позволяющих включить анализ больших массивов данных в принятие решений; ФР неверного выбора направлений модернизации информационных систем и т. п. В то же время необходима, как минимум, качественная оценка значимости ФР нарушения запланированных сроков реализации проекта, ФР увеличения объема затрат и т. п. 
В ряде случаев сроки реализации и бюджет проекта по внедрению новых цифровых технологий могут превышать запланированные сроки или утвержденные финансовые параметры проекта, а в некоторых случаях вообще проект не поддается реализации в целом. Безусловно, инвестиции в цифровые технологии связаны с общим повышением уровня риска недостижения намеченных промежуточных и итоговых результатов проекта, однако отказ от реализации проектов по внедрению цифровых технологий в изменяющихся условиях работы предприятия может привести к более худшим экономическим последствиям, например, к потере рынка или существенной его части.

4. Темпы внедрения цифровых технологий во внешней для предприятия среде становятся очень высокими, поэтому возрастает роль прогнозирования влияния того или иного изменения на отрасль в целом (то есть на средовую подсистему предприятия), а также роль эффективного применения этих знаний для формирования стратегии, с одной стороны, и для адаптации предприятия к этим изменениям, с другой. Даже ограниченное применение современных информационных технологий в рамках отдельных подразделений, например, в отделах, занимающихся разработкой новых продуктов и услуг, может помочь предприятию ранжировать освоение новых продуктов, заблаговременно разработать превентивные антирисковые мероприятия и опередить таким образом конкурентов при выводе на рынок новых товаров. Однако, и в этом случае весьма реально появление новых факторов экономического риска. Например, появление факторов риска несанкционированного использования денежных средств при использовании систем онлайн и мобильных платежей, что может быть связано с недостаточной защищенностью этих каналов. Аналогичные ситуации могут складываться с применением облачных технологий, которые не только позволяют сократить издержки предприятия, но и являются источниками новых ФЭР, связанных с местом хранения, изоляцией и защитой данных. В связи с этим вопросы защиты данных вынуждают предприятия вносить изменения еще и в практику использования облачных сервисов [2].

\section{Заключение}

Проведенное исследование показало, что существует сравнительно небольшое количество новых цифровых технологий, которые могут быстро дать значительный эффект, в то время как предприятию необходимо найти способ оценки этих технологий и расстановки приоритетов. Масштаб изменений бизнесмодели и сроки реализации проекта по внедрению новых цифровых технологий могут стать индикаторами оценки качества управления предприятием. Для этого в первую очередь необходимо, чтобы топ-менеджмент предприятия сформировал себе четкое представление о том, в какой точке движения к цели находится предприятие в данный момент, в каком направлении двигается и какие проекты могут позволить достичь желаемой цели в требуемые сроки.

ФЭР недостижения цели проекта внедрения новых цифровых технологий в сложной социально-экономической системе, которую представляет собой предприятие, сгруппированы по подсистемам в соответствии с новой экономической теорией. Показано, что предложенная структуризация пространства элементарных ФЭР может служить исходной точкой для развития нового направления прикладных исследований в области совершенствования качества управления производственными предприятиями.

Необходимо заметить, что даже успешные в своей отрасли предприятия не всегда могут добиться заметных позитивных изменений за короткий период. Тем не менее обретение высокого качества управления этими предприятиями позволяет оценить общий уровень риска до запуска следующей волны изменений, а также выявить наиболее перспективные инициативные проекты и критические факторы риска, которые могут этому помешать.

С учетом многообразия начальных условий, состояния экономических подсистем предприятия и поставленных целей, своевременное выявление факторов риска и их анализ может существенно повлиять на улучшение качества управления предприятием, а также на специфические характеристики внедренных цифровых информационных систем. 
Анализ показывает, что прикладные исследования процессов цифровизации в экономике и управлении микроэкономическими системами способствуют не только развитию методов анализа и управления уровнем экономического риска в этой предметной области, но и позволяют совершенствовать системы и качество управления предприятиями. Наряду с этим становится возможным переходить к формированию перспективных моделей взаимодействия с потребителями, основанных, в частности, на применении новых способов обработки сверхбольших массивов цифровой информации и т. п.

\section{СПИСОК ЛИТЕРАТУРЫ}

1. Винокуров, В. А. Качество управления как фактор укрепления рыночных позиций предприятия / В. А. Винокуров, А. А. Винокуров. Электрон. текстовые дан. - Режим доступа: http: //quality.eup.ru/MATERIALY11/qm-f.htm. - Загл. c экрана.

2. Информационная безопасность при облачных вычислениях: проблемы и перспективы / М. Я. Беккер, Ю. А. Гатчин, Н. С. Кармановский, А. О. Терентьев, Д. Ю. Федоров // Научно-технический вестник информационных технологий, механики и оптики. -2011 . - № 1 (71). - С. 97-102.

3. Качалов, Р. М. Управление экономическим риском: теоретические основы и приложения / Р. М. Качалов. -СПб. : Нестор-История, 2012. -288 c.

4. Качалов, Р. М. Структурирование системно-экономического пространства предприятия в задачах управления уровнем риска / Р. М. Качалов, Ю. А. Слепцова // Российский журнал менеджмента. -2015 . - Т. 13, № 4. - C. 69-84.

5. Клейнер, Г. Б. Новая теория экономических систем и ее приложения / Г. Б. Клейнер // Журнал экономической теории. - 2010. - № 3. - С. 41-58.

6. Клейнер, Г. Б. Системная экономика как платформа развития современной экономической теории / Г. Б. Клейнер // Вопросы экономики. 2013. -№ 6. - C. 4-28.

7. Кобылко, А. А. Видеопотребление как стратегический фактор развития операторов связи / А. А. Кобылко // Молодая экономика: экономическая наука глазами молодых ученых : материалы науч.практ. конф., Москва, 10 декабря 2014 г. / под ред. Р. Н. Павлова. - М. : ЦЭМИ РАН, 2014. - С. 79-82.

8. Королев, В. И. Качество управления предприятием: проблемы, пути повышения / В. И. Королев // Управленческие науки. - 2017. - № 1. C. 69-74.
9. Кэмпбелл, Э. Стратегический синергизм / Э. Кэмпбелл, К. Саммерс Лачс. - СПб. : Питер, 2004. $-416 \mathrm{c}$.

10. Лалу, Ф. Открывая организации будущего / Ф. Лалу. - М. : Манн, Иванов и Фербер, 2016. -88 с.

11. Литвак, Б. Г. Разработка управленческого решения / Б. Г. Литвак. - М. : Дело, 2008 - 392 с.

12. Манюкова, Н. В. Компьютерное зрение как средство извлечения информации из видеоряда / Н. В. Манюкова // Математические структуры и моделирование. - 2015. - № 4 (36). - С. 123-127.

13. Порфирьев, Б. Н. Альтернативная энергетика как фактор эколого-энергетической безопасности: особенности России / Б. Н. Порфирьев // Экономика региона. -2011. - № 2. - С. 137-145.

14. Приказ Министерства образования и науки Российской Федерации (Минобрнауки России) от 1 ноября 2012 г. № 881 «Об утверждении критериев отнесения товаров, работ, услуг к инновационной и высокотехнологичной продукции для целей формирования плана закупки такой продукции» // Российская газета. -2013. - 13 марта (№ 53).

15. Пряников, М. М. Блокчейн как коммуникационная основа формирования цифровой экономики: преимущества и проблемы / М. М. Пряников, А. В. Чугунов // International Journal of Open Information Technologies. - 2017. - № 6. -P. 49-55.

16. Райзберг, Б. А. Целевые программы в системе государственного управления экономикой / Б. А. Райзберг. - М. : Лаборатория Книги, 2012. $-332 \mathrm{c}$.

17. Ромашов, О. В. Формирование человеческого капитала в условиях инновационного развития российского общества / О. В. Ромашов // Вестник Московского государственного лингвистического университета. - Вып. 6 (692). - 2014. - С. 147-164.

18. Слепцова, Ю. А. Методы выбора антирисковых управленческих воздействий / Ю. А. Слепцова // Научно-технические ведомости Санкт-Петербургского государственного политехнического университета. Экономические науки. - 2015. - Вып. 6 (233). C. 222-232. - DOI: 10.5862/JE.233.23.

19. Соболева, И. В. Парадоксы измерения человеческого капитала / И. В. Соболева // Вопросы экономики. -2009 , сент. - № 9. - С. 51-70.

20. Формирование цифровой экономики в России: сущность, особенности, техническая нормализация, проблемы развития / А. В. Бабкин, Д. Д. Буркальцева, Д. Г. Костень, Ю. Н. Воробьев // Научно-технические ведомости Санкт-Петербургского государственного политехнического университета. Экономические науки. - 2017. - № 3. C. 9-22.

21. Цифровая экономика - различные пути к эффективному применению технологий (BIM, PLM, CAD, IOT, Smart City, Big Data и другие) 
/ А. П. Добрынин, К. Ю. Черных, В. П. Куприяновский, П. В. Куприяновский, С. А. Синягов // International Journal of Open Information Technologies. -2016. - Vol. 4, № 1. - C. 4-11.

22. Blundell-Wignall, A. The bitcoin question: Currency versus trust-less transfer technology / A. Blundell-Wignall // OECD Working Papers on Finance, Insurance and Private Pensions. - 2014. No. 37. - P. 3-21.

23. Internet Marketing, 4th edition / D. Chaffey, F. Ellis-Chadwick, R. Mayer, K. Johnston.Edinburgh : Pearson Education, 2009. - 702 p.

24. Yermak, D. Is bitcoin a real currency? / D. Yermak // NBER Working Paper. - 2013, Dec. № 19747. -P. 3-22.

\section{REFERENCES}

1. Vinokurov V.A., Vinokurov A.A. Kachestvo upravleniya kak faktor ukrepleniya rynochnykh pozitsiy predpriyatiya [Quality Management as a Factor of Strengthening Market Position of the Enterprise]. URL: http://quality.eup.ru/MATERIALY11/ qm-f.htm.

2. Bekker M.Ya., Gatchin Yu.A., Karmanovskiy N.S., Terentyev A.O., Fedorov D.Yu. Informatsionnaya bezopasnost pri oblachnykh vychisleniyakh: problemy i perspektivy [Information Security in Cloud Computing: Problems and Prospects]. Nauchno-tekhnicheskiy vestnik informatsionnykh tekhnologiy, mekhaniki i optiki, 2011, no. 1 (71), pp. $97-102$.

3. Kachalov R.M. Upravlenie ekonomicheskim riskom: teoreticheskie osnovy i prilozheniya [Economic Risk Management: Theoretical Foundations and Applications]. Saint Petersburg, Nestor-Istoriya Publ., 2012. 288 p.

4. Kachalov R.M., Sleptsova Yu.A. Strukturirovanie sistemno-ekonomicheskogo prostranstva predpriyatiya $\mathrm{v}$ zadachakh upravleniya urovnem riska [Structuring the System-Economic Space of an Enterprise in the Tasks of Managing the Level of Risk]. Rossiyskiy zhurnal menedzhmenta, 2015, vol. 13, no. 4, pp. 69-84.

5. Kleiner G.B. Novaya teoriya ekonomicheskikh sistem i ee prilozheniya [The New Theory of Economic Systems and Its Applications]. Zhurnal ekonomicheskoy teorii, 2010, no. 3, pp. 41-58.

6. Kleiner G.B. Sistemnaya ekonomika kak platforma razvitiya sovremennoy ekonomicheskoy teorii [System Economy as a Platform for the Development of Modern Economic Theory ]. Voprosy ekonomiki, 2013, no. 6, pp. 4-28.

7. Kobylko A.A. Videopotreblenie kak strategicheskiy faktor razvitiya operatorov svyazi
[Video Consumption as a Strategic Factor in Telecom Operators Development]. Pavlov R.N., ed. Molodaya ekonomika: ekonomicheskaya nauka glazami molodykh uchenykh: materialy nauch.-prakt. konf., Moskva, 10 dekabrya 2014 g. [Young Economy: Economics as Viewed by Young Scientists. Proceedings of Research and Practice Conference, Moscow (December 10, 2014)]. Moscow, TsEMI RAN Publ., 2014, pp. 79-82.

8. Korolev V.I. Kachestvo upravleniya predpriyatiem: problemy, puti povysheniya [Quality of Enterprise Management: Problems, Ways to Improve]. Upravlencheskie nauki, 2017, no. 1, pp. 69-74.

9. Campbell A., Summers K. Strategicheskiy sinergizm [Strategic Synergy]. Saint Petersburg, Piter Publ., 2004. 416 p.

10. Lalu F. Otkryvaya organizatsii budushchego [Reinventing Organizations: A Guide to Creating Organizations Inspired by the Next Stage of Human Consciousness]. Moscow, Mann, Ivanov i Ferber Publ., 2016. 88 p.

11. Litvak B.G. Razrabotka upravlencheskogo resheniya [Development of Management Solutions]. Moscow, Delo Publ., 2008. 392 p.

12. Manyukova N.V. Kompyuternoe zrenie kak sredstvo izvlecheniya informatsii iz videoryada [Computer Vision as a Means of Extracting Information from Video Sequence]. Matematicheskie struktury $i$ modelirovanie, 2015, no. 4 (36), pp. 123-127

13. Porfiryev B.N. Alternativnaya energetika kak faktor ekologo-energeticheskoy bezopasnosti: osobennosti Rossii [Alternative Energy as a Factor of Ecological and Energy Security: Features of Russia]. Ekonomika regiona, 2011, no. 2, pp. 137-145.

14. Prikaz Ministerstva obrazovaniya i nauki Rossiyskoy Federatsii (Minobrnauki Rossii) ot 1 noyabrya 2012 g. N 881 g. Moskva «Ob utverzhdenii kriteriev otneseniya tovarov, rabot, uslug k innovatsionnoy i vysokotekhnologichnoy produktsii dlya tseley formirovaniya plana zakupki takoy produktsii» [Order of the Ministry of Education and Science of the Russian Federation of 1 November 2012 No. 881, Moscow 'On Approving Criteria of Allocating Goods, Works and Services to Innovative and HighTech Products for the Purpose of Making up the Plans of Procurement of Such Products]. Rossiyskaya gazeta, 2013, no. 53 (March 13).

15. Pryanikov M.M., Chugunov A.V. Blokcheyn kak kommunikatsionnaya osnova formirovaniya tsifrovoy ekonomiki: preimushchestva i problemy [Blockchain as a Communication Basis for Digital Economy Formation: Advantages and Problems]. International Journal of Open Information Technologies, 2017, no. 6, pp. 49-55.

16. Rayzberg B.A. Tselevye programmy v sisteme gosudarstvennogo upravleniya ekonomikoy [Target 
Programs in the System of Economy's State Management]. Moscow, Laboratoriya knigi Publ., 2012. 332 p.

17. Romashov O.V. Formirovanie chelovecheskogo kapitala $\mathrm{v}$ usloviyakh innovatsionnogo razvitiya rossiyskogo obshchestva [Formation of Human Capital in the Conditions of Innovative Development of Russian Society]. Vestnik Moskovskogo gosudarstvennogo lingvisticheskogo universiteta, 2014, iss. 6 (692), pp. 147-164.

18. Sleptsova Yu.A. Metody vybora antiriskovykh upravlencheskikh vozdeystviy [Methods of Selecting Anti-Risk Controlling Actions]. Nauchnotekhnicheskie vedomosti Sankt-Peterburgskogo gosudarstvennogo politekhnicheskogo universiteta. Ekonomicheskie nauki, 2015, iss. 6(233), pp. 222-232. DOI: $10.5862 / J E .233 .23$

19. Soboleva I.V. Paradoksy izmereniya chelovecheskogo kapitala [Paradoxes of Measuring Human Capital]. Voprosy ekonomiki, 2009, no. 9, pp. 51-70.

20. Babkin A.V., Burkaltseva D.D., Kosten D.G., Vorobyev Yu.N. Formirovanie tsifrovoy ekonomiki v Rossii: sushchnost, osobennosti, tekhnicheskaya normalizatsiya, problemy razvitiya [Formation of Digital Economy in Russia: Essence, Features, Technical
Normalization, Development Problems]. Nauchnotekhnicheskie vedomosti Sankt-Peterburgskogo gosudarstvennogo politekhnicheskogo universiteta. Ekonomicheskie nauki, 2017, vol. 10 (3), pp. 9-25. DOI: $10.18721 / \mathrm{JE} .10301$

21. Dobrynin A.P., Chernykh K.Yu., Kupriyanovskiy V.P., Kupriyanovskiy P.V., Sinyagov S.A. Tsifrovaya ekonomika - razlichnye puti k effektivnomu primeneniyu tekhnologiy (BIM, PLM, CAD, IOT, Smart City, Big Data i drugie) [Digital Economy - Various Ways to Efficient Application of Technologies (BIM, PLM, CAD, IOT, Smart City, Big Data, etc.)]. International Journal of Open Information Technologies, 2016, vol. 4, no. 1, pp. 4-11.

22. Blundell-Wignall $\mathrm{A}$. The bitcoin question: Currency versus trust-less transfer technology. OECD Working Papers on Finance, Insurance and Private Pensions, 2014, No. 37, pp. 3-21.

23. Chaffey D., Ellis-Chadwick F., Mayer R., Johnston K. Internet Marketing. Edinburgh, Pearson Education, 2009. 702 p.

24. Yermak D. Is bitcoin a real currency? NBER Working Paper, 2013, No. 19747, pp. 3-22.

\section{Information about the Authors}

Roman M. Kachalov, Doctor of Sciences (Economics), Head of Laboratory of Publishing and Marketing Activity, Central Economics and Mathematics Institute of Russian Academy of Sciences, Prosp. Nakhimovskiy, 47, 117418 Moscow, Russian Federation, kachalov@cemi.rssi.ru.

Yuliya A. Sleptsova, Candidate of Sciences (Economics), Senior Researcher, Laboratory of Publishing and Marketing Activity, Central Economics and Mathematics Institute of Russian Academy of Sciences, Prosp. Nakhimovskiy, 47, 117418 Moscow, Russian Federation, julia_sleptsova@mail.ru.

\section{Информация об авторах}

Роман Михайлович Качалов, доктор экономических наук, заведующий лабораторией издательской и маркетинговой деятельности, Центральный экономико-математический институт PAH, просп. Нахимовский, 47, 117418 г. Москва, Российская Федерация, kachalov@cemi.rssi.ru.

Юлия Анатольевна Слепцова, кандидат экономических наук, старший научный сотрудник лаборатории издательской и маркетинговой деятельности, Центральный экономико-математический институт РАН, просп. Нахимовский, 47, 117418 г. Москва, Российская Федерация, julia_sleptsova@mail.ru. 